\title{
Evaluation of phenotypic and genotypic alterations induced by long periods of subculturing of Cryptococcus neoformans strains
}

\author{
Sonia Cristina Cavalcante ${ }^{+}$, Roseli Santos Freitas, Mônica Scarpelli Martinelli Vidal, \\ Kátia Cristina Dantas, José Eduardo Levi*, José Eduardo Costa Martins
}

\author{
Laboratório de Micologia Médica *Laboratório de Virologia, Instituto de Medicina Tropical de São Paulo/LIM-53/52*, \\ Rua Dr. Enéas de Carvalho Aguiar 500, 05403-000 São Paulo, SP, Brasil
}

Cryptococcus neoformans is an encapsulated fungal organism that can cause disease in apparently immunocompetent, as well as immunocompromised, hosts. Since 1930, successive subculture has been used to preserve C. neoformans isolates in our Fungus Collection. In the 1970s, some of these Fungus Collection samples were selected to be subjected to a different methods of maintenance - that of lyophilized. Our objective was to analyze C. neoformans isolates in order to make a comparative evaluation between these two methods of preservation. The overall aim of this study was to qualify the preservation technique used in our mycology laboratory since the technique used might affect the survival, stability and purity of the primary isolates in culture.

The samples were analyzed using classical mycology methods and using the randomly amplified polymorphic DNA technique. In the analysis of phenotypes and genotypes, the typical characteristics of $\mathrm{C}$. neoformans were found to differ in relation to the different methods of preservation employed.

The aim of this study was to demonstrate the importance of selecting the appropriate method of preservation for fungus collections. This selection can affect the survival and purity of the cultures, and preserve the stability of their physiological, biochemical, and genetic characteristics.

Key words: Cryptococcus neoformans - random amplified polymorphic DNA technique - freeze drying

Cryptococcus neoformans is a basidiomycetous, the etiologic agent of cryptococcosis, yeast-like fungus which, following inhalation from an environmental source causes respiratory and neurological disease in humans and animals. Cryptococcal infections can be fatal if the host does not have adequate T-cell-dependent immune function. Most important predisposing factors for infection with $C$. neoformans are virus immunodeficiency infection, use of immunosuppressive drugs, organ and bone marrow transplantation, chronic leukemia, and lymphomas (Dismukes 1988, Velegraki, et al. 2001, Horta et al. 2002).

Kwon-Chung et al. (1982) established two varieties that were recognized: var. neoformans and var. gattii. Currently we recognize 3 varieties: grubii - serotype A-, gattii serotype B, C, - and neoformans - serotype D (Franzot et al. 1999). Most likely, var. gattii will be renamed as a novel species and called C. bacillisporus (Diaz et al. 2000).

This fungus appears in yeast form, presenting spherical cells $(5-100 \mu \mathrm{m}$ in diameter) with single or multiple buds. The colonies are cream-colored, glossy, viscous, and moist, the amount of mucous being directly related to the size of the capsule. Among the various

Financial support: Fapesp

${ }^{+}$Corresponding autor: soniamicologia@yahoo.com

Received 2 June 2006

Accepted 4 October 2006 virulence factors, the most significant are capsular polysaccharides such as glucuronoxylan, galactoxilamanane, and mannoproteins (Kurtzman \& Fell 1998, Lacaz et al. 2002, Chiapello et al. 2003, Ellerbroek et al. 2004).

The samples of $C$. neoformans maintained in our Fungus Collection are especially useful for biotechnology projects, scientific research related to antifungal therapy, determination of molecular characteristics, production antigen, and instructional programs, as well as functional as reference cultures. Various preservation techniques are used: successive subculture on solid medium (with or without the addition of mineral oil); spore cultivation (in soil, sand, or silica gel); lyophilized; liquid nitrogen storage; and suspension in distilled water (Castellani 1963, 1967, Urdaneta et al. 1965, Bosmans 1974, Rodrigues et al. 1992, Cavalcanti \& Cavalcanti 1994, Spencer \& Spencer 1996).

With the advent of molecular biology, various techniques have come to be used to analyze the genotype of the potential polymorphism of fungus samples. These include randomly amplified polymorphic DNA (RAPD), pulsed-field gel electrophoresis, (PFGE), restriction fragment length polymorphism (RFLP), and amplified fragment length polymorphism (AFLP). The cost of performing the RFLP, PFGE, and AFLP techniques is prohibitive. However, the RAPD method can be performed at a relatively low cost. This technique suits our needs perfectly, not only due to its cost-effectiveness but also to its reproducibility (Willians 1990).

In our Fungus Collection, samples of $C$. neoformans have been maintained in successive subcultures since 1930. In the 1970s, some of these samples were selected 
to be stored using the lyophilization technique. The preservation method of choice in our laboratory is still successive subculture since it is considered a simple method and is quite cost-effective.

Our objective was to carry out a comparative evaluation between the $C$. neoformans isolates maintained by successive subcultures and those maintained lyophilized. The molecular biology techniques used allowed us to better characterize the genotype represented in these samples.

\section{MATERIALS AND METHODS}

We studied eight $C$. neoformans strains from the Fungus Collection of the Tropical Medicine Institute in São Paulo, Brazil. These samples had been isolated from biological material (liquor) collected from patients.

"Fungus Collection" (FC) samples were maintained using lyophilization, stored at $4^{\circ} \mathrm{C}$ and designated "Lyophilized" (L). The L samples were hydrated in Sabouraud dextrose broth and seeded on Sabourauddextrose agar with chloramphenicol. The colonies that presented growth were re-identified and designated "Viable" (V). (Fig. 1).

All of the samples were identified as to genus and species through the characterization of a single colony, by direct examination with India ink, determination of

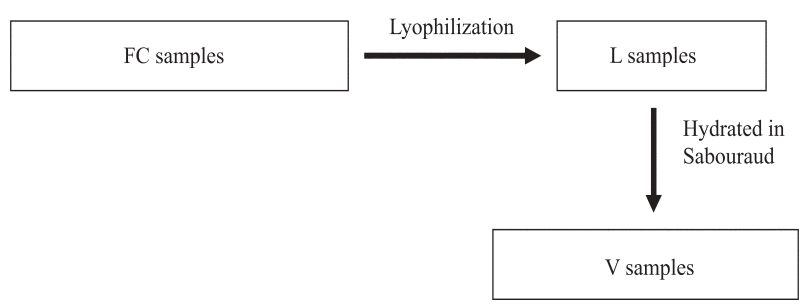

Fig. 1: description of obtained the samples. FC: Fungus Collection; L: lyophilized; V: viable.

urease activity, inositol biosynthesis, carbon/nitrogen (nitrate) source assimilation, melanin production on Niger agar medium (McGinnis 1980, Kwon-Chung et al. 1982). The serotyping $C$. neoformans in these strains (Lacaz \& Rodrigues 1983) and the biochemical tests have been used to differentiate $C$. neoformans from variety gattii on the basis of resistance to canavanine, conversion of glycine to ammonia, and assimilation of certain dicaboxylic acids (Bennett et al. 1978, KownChung et al. 1982).

To extract DNA, yeasts obtained from FC and L samples maintained through successive subculture were used: (1) dehydrated L yeasts and (2) V yeasts cultured on Sabouraud-dextrose agar.

DNA extraction - The samples were cultured on Sabouraud-dextrose agar medium supplemented with $2.9 \% \mathrm{NaCl}$ in order to remove the capsule. They were then cultured in $10 \mathrm{ml}$ of yeast-peptone-dextrose (YPD) liquid medium with $2.9 \% \mathrm{NaCl}$ at $25^{\circ} \mathrm{C}$ for $18 \mathrm{~h}$ under constant agitation.

The cell cultures were washed with $50 \mathrm{mM}$ of EDTA at $\mathrm{pH} 8.0$, and the optical density (OD) was quantified in a spectrophotometer $(\mathrm{OD}=550 \mathrm{~nm})$. Subsequently, we transferred $200 \mathrm{mg}$ of the culture to another tube and added $600 \mu \mathrm{l}$ of sorbitol buffer (1 M Sorbitol, $100 \mathrm{mM}$ EDTA, and $14 \mathrm{mM} \beta$ mercaptoethanol), followed by 48 $\mu 1$ (200 U) of the enzyme lyticase (Sigma Chemical Co., St. Louis, MO, US). The resulting culture was incubated for $30 \mathrm{~min}$ at $30^{\circ} \mathrm{C}$ and centrifuged for $5 \mathrm{~min}$ at 7500 rpm. The supernatant was discarded. The spheroplasts were resuspended in a solution containing $180 \mathrm{ml}$ of a tissue lyses buffer (ATL; QIAgen, Valencia, CA, US) and $20 \mu \mathrm{l}$ of the enzyme Proteinase K (100 mg/ml; QIAgen), which was then incubated overnight at $56^{\circ} \mathrm{C}$. Extraction and purification of the total DNA were performed in accordance with the QIAamp DNA Mini Kit (QIAgen) protocol.

A polymerase chain reaction (PCR) analysis (universal primer $28 \mathrm{~S} r D N A$ ) - For detection of the $28 \mathrm{~S}$ conserved region in all of the fungus samples, the PCR was conducted using the primer pairs P1/P2 (ATC AAT AAG CGC AGG AAA A and CTC TGG CTT CAC CCT ATT C, respectively) and U1/U2 (GTG AAA TTG AAA GGG AA and GAC TCC TTG GTC CGT GTT, respectively). The human $28 \mathrm{~S}$ gene was not amplified. The P1 primer corresponds to the 45-to 64-bp region of the gene, and the P2 primer corresponds to the 825- to 843bp region, which is used as a reference point for the 28 $\mathrm{S}$ region of the Saccharomyces cerevisiae gene (Gen Bank accession no. J01355). The P1/P2 primer pair detected a 799-bp fragment. The U1 primer corresponds to the 403 - to $422-\mathrm{bp}$ region, and the $\mathrm{U} 2$ primer corresponds to the 645- to 662-bp region. The reference gene used for the $28 \mathrm{~S}$ conserved region was the same as that used for the $\mathrm{P} 1 / \mathrm{P} 2$ primer pair described above. The U1/U2 primer pair detected a 260-bp fragment (Sandhu et al. 1995).

The PCR amplification condition conditions for the P1/P2 and U1/U2 primer pair were as follows: we used $750 \mathrm{ng} / \mu \mathrm{l}$ of DNA, $0.2 \mathrm{mM}$ of deoxynucleoside triphosphate (dNTP, Invitrogen, Carlsbad, CA, US), $1 \times$ PCF buffer (potassium chloride, $30 \mathrm{mM}$, Tris, $10 \mathrm{mM}$; $\mathrm{pH}$ $8,3), 1.5 \mathrm{mM}$ of $\mathrm{MgCl}$ (Invitrogen), $1 \mathrm{U}$ of Taq DNA polymerase (Invitrogen), $0.4 \mu \mathrm{M}$ each of the sense primer $(\mathrm{P} 1 / \mathrm{U} 1)$ and the antisense primer $(\mathrm{P} 2 / \mathrm{U} 2)$ - in a final volume of $25 \mu \mathrm{l}$. For both primer pairs, amplification was carried out using a total of 50 cycles: $30 \mathrm{~s}$ at $94^{\circ} \mathrm{C}$; $1 \mathrm{~min}$ at $50^{\circ} \mathrm{C}$; and $2 \mathrm{~min}$ at $72^{\circ} \mathrm{C}$ (Thermo Electron Corporation, Waltham, MA, US).

For viewing, the amplified DNA was electrophoresed on a $1.5 \%$ agarose gel in $1 \mathrm{x}$ Tris-acetate-EDTA (TAE) buffer (400 mM Tris-acetate and $100 \mathrm{mM}$ EDTA, pH 8.3 ) for 40 min at 80 volts, stained with ethidium bromide in a final concentration of $10 \mathrm{mg} / \mathrm{ml}$. The molecular weight standard used was a 1-kb DNA ladder (Invitrogen), and the product was viewed under UV light.

$R A P D$ reaction - For the RAPD technique of amplification, we used $200 \mathrm{ng}$ of fungal DNA, $0.4 \mathrm{mM}$ of primer 1 (CCCGTCAGCA; Invitrogen), $0.4 \mathrm{mM}$ of dNTP 
(Invitrogen), $1 \mathrm{U}$ of Taq DNA polymerase (Invitrogen); $1 \times$ PCR buffer (potassium chloride, $30 \mathrm{mM}$; Tris 10 $\mathrm{mM}, \mathrm{pH}$ 8.3; Invitrogen), and $3 \mathrm{mM}$ of $\mathrm{MgCl} 2$ (Invitrogen) - in a final volume of $25 \mu \mathrm{l}$. A total of 44 cycles were completed: $5 \mathrm{~min}$ at $95^{\circ} \mathrm{C} ; 1 \mathrm{~min}$ at $36^{\circ} \mathrm{C} ; 2$ min at $72^{\circ} \mathrm{C}$; and a final extension of $10 \mathrm{~min}$ at $72^{\circ} \mathrm{C}$. For the amplification of the second round reaction, primer 2 (AACGCGCAAC) was used under the same conditions described for primer 1 . These reactions were performed in triplicate in order to determine the reproducibility of the results obtained. The amplified DNA was observed using electrophoresis on a $1 \%$ agarose gel in 1 x TAE buffer for 40 min at 80 volts. The molecular weight standard used was a 1-kb DNA ladder (Invitrogen). The product was stained with ethidium bromide in a final concentration of $10 \mathrm{mg} / \mathrm{ml}$ and was viewed under UV light.

\section{RESULTS}

Mycological analysis - Table shows that the FC samples presented growth after $48 \mathrm{~h}$, with the exception of FC sample 3, whereas $\mathrm{V}$ samples presented growth after $72 \mathrm{~h}$. Colonies in all of the FC samples were shiny and moist, whereas those in the L samples were opaque and dry (Fig. 2). In the microscopic analysis, we observed that FC sample cells presented large capsules and budding, in contrast to the small capsules (also with budding) seen in the V sample cells (Fig. 3).

The colonies initiated melanin production after five days in culture, presenting dark brown staining (Fig. 4).

TABLE

Phenotypical and genotypical analysis of the Cryptococcus neoformans samples

\begin{tabular}{|c|c|c|c|c|c|c|}
\hline \multicolumn{3}{|c|}{$\begin{array}{l}\text { Strain } \\
\text { time to growth } \\
\text { (hours) }\end{array}$} & \multirow{2}{*}{$\begin{array}{l}\text { Macroscopic analysis } \\
\text { Opaque and dry }\end{array}$} & \multirow{2}{*}{$\begin{array}{l}\text { Microscopic }{ }^{a} \text { analysis } \\
\text { Small capsule with buds }\end{array}$} & \multirow{2}{*}{$\begin{array}{l}\text { Biochemistry analysis }^{a, b} \\
\text { Serotype A, var. neoformans, assimilation }^{d}\end{array}$} & \multirow{2}{*}{$\begin{array}{c}\text { RAPD } \\
\text { band } \\
\text { profiles }^{c}\end{array}$} \\
\hline 1 & $\mathrm{~V}$ & 72 & & & & \\
\hline & $\mathrm{FC}$ & 48 & Glossy and moist & Large capsule with buds & Serotype A, var. neoformans, assimilation all & 6 \\
\hline & $\mathrm{L}$ & - & - & - & - & 7 \\
\hline \multirow[t]{3}{*}{2} & $\mathrm{~V}$ & 72 & Opaque and dry & Small capsule with buds & Serotype A, var. neoformans, assimilation ${ }^{d}$ & 9 \\
\hline & $\mathrm{FC}$ & 48 & Glossy and moist & Large capsule with buds & Serotype A, var. neoformans, assimilation $d$ & 7 \\
\hline & $\mathrm{L}$ & - & - & - & - & 8 \\
\hline \multirow[t]{4}{*}{3} & $\mathrm{~V}$ & 72 & Opaque and dry & Small capsule with buds & Serotype B, var. gattii assimilation ${ }^{d}$ & 7 \\
\hline & $\mathrm{FC}$ & 72 & Glossy and moist & Large capsule with buds & Serotype B, var. gattii assimilation ${ }^{d}$ & 7 \\
\hline & $\mathrm{L}$ & - & - & & - & 4 \\
\hline & & & & - & & \\
\hline \multirow[t]{3}{*}{4} & $\mathrm{~V}$ & 72 & Opaque and dry & Small capsule with buds & Serotype A, var. neoformans, assimilation ${ }^{d}$ & 7 \\
\hline & $\mathrm{FC}$ & 48 & Glossy and moist & Large capsule with buds & $\begin{array}{l}\text { Serotype A, var. neoformans, xylose negative; } \\
\text { melibiose positive }\end{array}$ & 8 \\
\hline & $\mathrm{L}$ & - & - & - & - & 5 \\
\hline \multirow[t]{3}{*}{5} & $\mathrm{~V}$ & 72 & Opaque and dry & Small capsule with buds & Serotype B, var. gattii assimilation ${ }^{d}$ & 5 \\
\hline & $\mathrm{FC}$ & 48 & Glossy and moist & Large capsule with buds & Serotype B, var. gattii assimilation ${ }^{d}$ & 6 \\
\hline & $\mathrm{L}$ & - & - & - & - & 4 \\
\hline \multirow[t]{3}{*}{6} & $\mathrm{~V}$ & 72 & Opaque and dry & Small capsule with buds & Serotype A, var. neoformans, assimilation ${ }^{d}$ & 6 \\
\hline & $\mathrm{FC}$ & 48 & Glossy and moist & Large capsule with buds & Serotype A, var. neoformans, assimilation $d$ & 6 \\
\hline & $\mathrm{L}$ & - & - & - & - & 6 \\
\hline \multirow[t]{3}{*}{7} & $\mathrm{~V}$ & 72 & Opaque and dry & Small capsule with buds & Serotype B, var. gattii assimilation ${ }^{d}$ & 9 \\
\hline & $\mathrm{FC}$ & 48 & Glossy and moist & Large capsule with buds & Serotype B, var. gattii assimilation ${ }^{d}$ & 5 \\
\hline & $\mathrm{L}$ & - & - & - & - & 2 \\
\hline \multirow[t]{3}{*}{8} & $\mathrm{~V}$ & 72 & Opaque and dry & Small capsule with buds & Serotype B, var. gattii assimilation ${ }^{d}$ & 8 \\
\hline & FC & 48 & Glossy and moist & Large capsule with buds & Serotype B, var. gattii galactose negative & 7 \\
\hline & $\mathrm{L}$ & - & - & - & - & 8 \\
\hline
\end{tabular}

$a$ : methodology devised by Kwon-Chung et al 1992; $b$ : assimilation of carbon and nitrogen compounds of C. neoformans; $c$ : number of bands per strain; $d$ : all samples presented characteristics typical of of $C$. neoformans. FC: Fungus Collection; L: lyophilized; V: viable. 


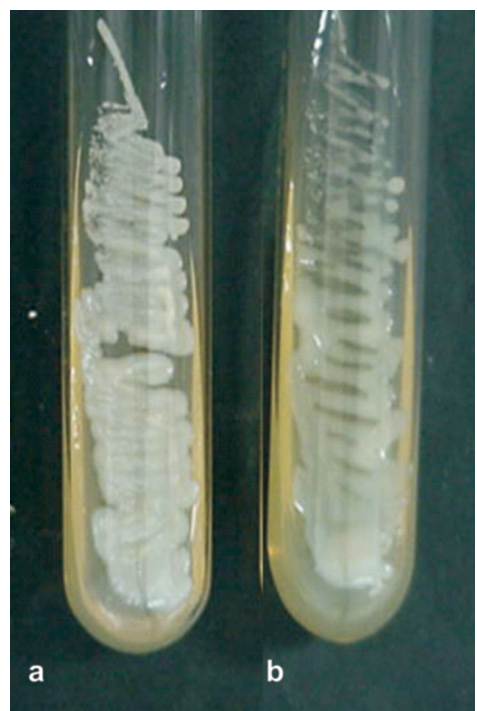

Fig. 2: macromorphology showing altered mucoid aspect. a: strain $1 \mathrm{~V}-$ opaque and dry; b: strain 1 FC - bright and humid.

All C. neoformans $\mathrm{L}$ samples were viable after having been maintained in a latent state for a period of approximately 30 years.

Biochemical analysis - All FC and V samples tested negative for nitrogen use and positive for urease activity. In testing the samples for assimilation of carbohydrates, we found that FC sample 8 did not assimilate galactose; and in the FC sample 4 we did not observe xylose assimilation but melibiose assimilation. We then analyzed the biochemical tests specific for the identification of the variety and serotype and observed that $50 \%$ of the samples $(1,2,4$, and 6$)$ are $C$. neoformans var. neoformans, serotype A, and $50 \%$ of the samples $(3,5,7$, and 8$)$ are $C$. neoformans var. gattii, serotype B.

Molecular analysis - Using the fungus-specific primer pair (U1/U2) to analyze the $28 \mathrm{~S}$ conserved region of the DNA of the samples, we found a 266-bp band

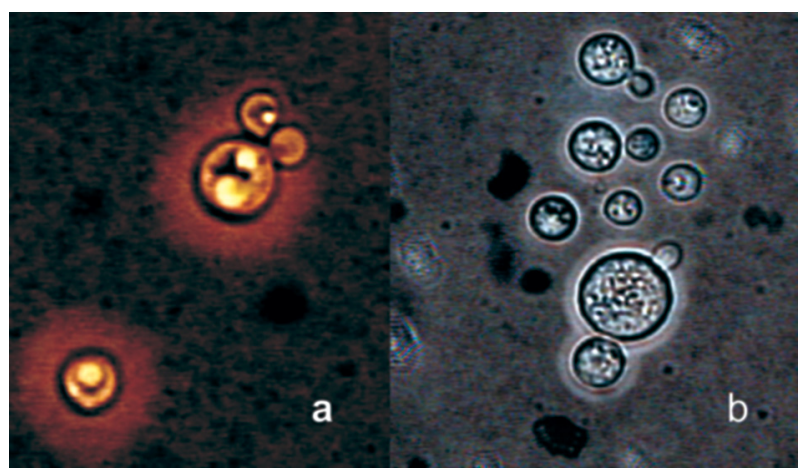

Fig. 3: micromorphology shows reduction of capsule sizes between strains. a: strain 4 FC - large capsule with buds; b: strain $4 \mathrm{~V}$ - small capsule with buds.

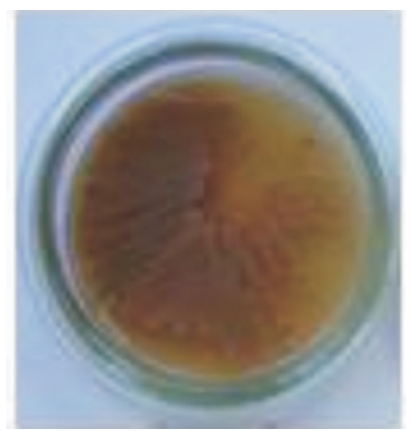

Fig. 4: melanin production in strain $3 \mathrm{~V}$ sample. The samples was cultured on Niger seed Agar medium. The colonies initiated melanin production after five days in culture, presenting dark-brown staining.

(Fig. 5).

PCR-RAPD analysis - The PCR-RAPD reaction was performed in triplicate, and the results obtained presented good reproducibility. The analysis was made based on the number and position, and not on the intensity, of the visible bands. The profiles of the bands obtained presented fractions ranging from $100 \mathrm{bp}$ to $2000 \mathrm{bp}$. Primer 1 (Fig. 6) presented better discrimination than did primer 2 (data not show).

Table shows that, in analyzing the RAPD results, the samples can be subdivided into four groups. Group I: presenting the same $\mathrm{FC}, \mathrm{V}$, and $\mathrm{L}$ band profiles (strain 6); Group II: presenting the same profile in $\mathrm{V}$ and $\mathrm{FC}$ bands only (strains 1 and 3); Group III: presenting no matching bands (strains 2, 4, 5, and 7); Group IV: presenting the same profile in $\mathrm{V}$ and $\mathrm{L}$ bands only (strain 2).

\section{DISCUSSION}

C. neoformans can cause disease in apparently immunocompetent, as well as, immunocompromised hosts

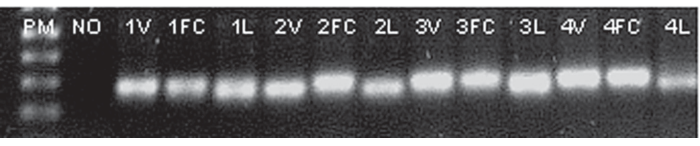

Fig. 5: polymerase chain reaction analysis (28S rDNA universal primer). The U1/U2 primer pair used for the preliminary amplification showed just one defined specific band, at $266 \mathrm{bp}$ for all strains. PM: molecular weight marker (1-kb DNA Ladder); No: negative control.

and from 1981 its incidence has increased dramatically as a result of the ongoing AIDS epidemic (Piot et al. 2001). In most Western countries $5-10 \%$ of HIV infected patients will develop cryptococcosis (Powderly 1993). Mortality of cryptococcosis is high. Between 10 and $25 \%$ of AIDS patients die during initial treatment, and between 30 and $60 \%$ of patients succumb within 12 months (Saag et al. 1992, van der Horst et al. 1997). The introduction of HAART has dramatically changed the course of HIV infection (Palella et al. 1998).

Recent studies of the various preservation methods 

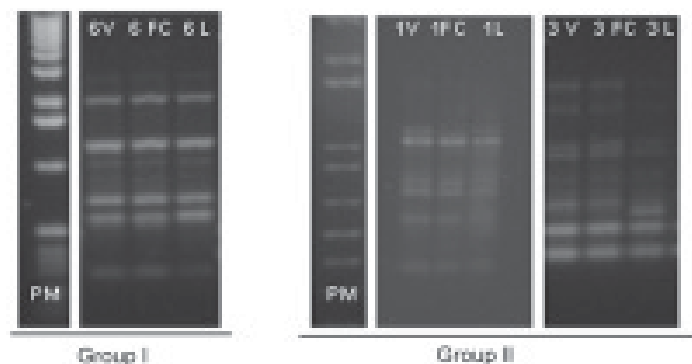

Group li
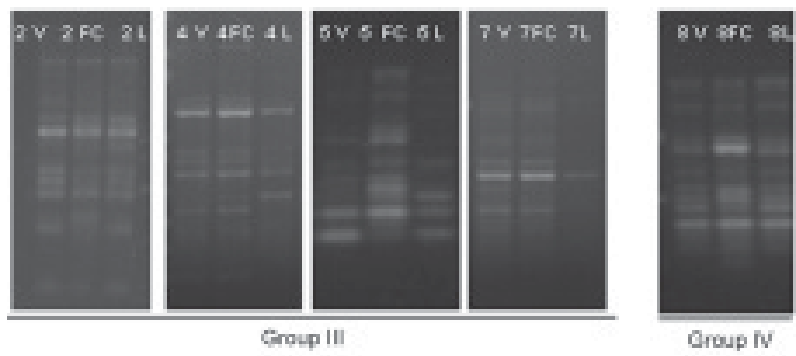

Fig. 6: randomly amplified polymorphic DNA results with primer 1 (10 bp) of Cryptococcus neoformans strains (FC, V, and L). PM: molecular weight marker (1-kb DNA Ladder). The samples were subdivided into four distinct groups (I, II, III, IV) based on similarities.

described above have aimed to determine the viability, maintenance of morphological characteristics, and maintenance of physiological characteristics and virulence of the various species of fungus. In these studies, varying results were obtained regarding phenotypic and genotypic traits. It has been shown that some fungus samples lose their capacity to sporulate and, in others, the virulence is attenuated, the latter being restored, in some cases, through inoculation in animals (Mendes da Silva et al. 1994, Borba \& Rodrigues 2000, Lima \& Borba 2001).

The macromorphological and micromorphological results obtained for the C. neoformans samples maintained through successive subculture and lyophilized revealed significant alterations, as much in the growth rates as in the physical appearance of the colonies and in the size of the capsules surrounding the cells.

The phenotypic characteristics, which were maintained in the FC samples (except in FC sample 3), can be explained by the enzymes active in the metabolic absorption and degradation of nutrients, as well as in the multiplication of cells that remain unaltered in the successive subcultures. However, some biochemical characteristics are altered by this method of preservation, as evidenced by the capacity to assimilate galactose (FC sample 8), xylose, and melibiose (FC sample 4).

In the $\mathrm{L}$ samples of $C$. neoformans, we observed macromorphological and micromorphological alterations, although we found no biochemical changes. In these samples, the cell metabolism was slowed to the level of artificial (latent) dormancy, which reduced the rate of growth and limited the real capacity of the species to perform enzymatic processes. Such aspects normalize over time. We observed that the different phenotypes between the viable samples maintained in a latent state for a period of approximately 30 years and the correspondent FC samples may be only transient. Jain et al. (2005) analyzed the phenotypic switching that occurred from in vivo to in vitro cultures in C. neoformans var. gattii (serotype B) as well as in the serotype A and D was associated with changes in the polysaccharide capsule and in virulence. In contrast to the serotype A and D strains, the serotype B strain switch was reversible. These authors suggest that this phenomenon is due to the in vivo selection pressure in both variants. Smooth colonies are rarely observed with $C$. neoformans var. gattii strains. This may be due to the fact that the switch in colony morphology possibly represent a "locked in" phenotype, usually transient, and thus difficult to be detected.

C. neoformans strains exists as five serotypes (A, B, $\mathrm{C}, \mathrm{D}, \mathrm{AD})$, based on differences in the capsule that consists of $88 \%$ of glucuronoxylomannan structure (Cherniak 1988). In this study we observed that $50 \%$ of the strains are $C$. neoformans var. neoformans, serotype A and $50 \%$ are C. neoformans var. gattii, serotype B. C. neoformans var. gattii is predominately restricted to tropical regions; however, a recent outbreak of $C$. neoformans var. gattii infections on Vancouver Island in Canada (Hoang et al. 2004) has raised the level of interest in this pathogen. Except for the recently described high prevalence of serotype $\mathrm{C}$ infections in AIDS patients living in sub-Saharan Africa (Litvintseva et al. 2005), the majority of cryptococcosis due to serotype B and C strains occurs in immunologically normal individuals. Disease with serotype A and D strains occurs more often in immunosuppressed hosts (Chen et al. 2000) but has also been described for immunocompetent patients (Jain et al. 2005).

In the biochemical analysis, the majority of samples presented characteristics typical of the results of the phenotyping of $C$. neoformans samples were confirmed through RAPD genotyping. The samples were grouped according to their individual band profiles and not based on band intensity. Distinct groups (Group I: presenting the same FC, V, and L band profiles; Group II: presenting the same profile in V and FC bands only; Group III: presenting no matching bands; Group IV: presenting the same profile in $\mathrm{V}$ and $\mathrm{L}$ bands only) were defined.

Nakamura (2001) investigated the serotype $C$ of $C$. neoformans using molecular analysis technique instead of the immunological method based on antisera against the capsule component of the yeast. For easier and more precise epidemiological surveillance, 27 isolates of $C$. neoformans were molecularly analyzed by the RAPD method and the authors observed that this method can further differentiate the isolates of C. neoformans.

The results obtained using the RAPD technique demonstrated that at least some of the FC samples were contaminated, as were some of the L samples, in which we observed molecular changes evidenced by the 
presence or absence of bands among samples within the same group. These data confirm that the FC method of preservation, despite its cost-effectiveness and ease of application, can cause serious contamination problems and may lead to loss of the cell line and to selection of atypical cells (variants or mutants). The samples preserved using the $\mathrm{L}$ technique also presented alterations, a finding, which we can assume is related to the fact that these samples were not lyophilized from the primary isolation but rather after having first been submitted to successive subcultures.

Igreja et al. (2004) observed that high biodiversity of $C$. neoformans isolates exists in some Brazilian urban areas. The authors analyzed by PCR fingerprinting, and RAPD isolates from Brazilian patients and showed that persistent cryptococcal infection was caused by relapse rather than re-infection, but rarely patients may be infected with more than one $C$. neoformans strain.

We can conclude that, due to the amount of specialized and supervised manual labor required to guarantee the purity of the samples and quality control in general, the method of preserving isolates previously used in our laboratory is not recommended for use with large collections of fungus samples. In view of these findings, we are reformulating our methods of storing C. neoformans samples, with the ultimate goal of maintaining the characteristics of the primary isolate. Achieving this goal will allow us to use these samples with confidence in mycology studies and in molecularbased studies with biotechnology applications, as well as in the production of specific antigens that would facilitate cryptococcosis diagnosis. The RAPD technique in our laboratory was considered perfect, not only due to its cost-effectiveness but also to its reproducibility and can use allowed us to further and better characterize the genotypes represented in fungal samples.

\section{ACKNOWLEDGMENTS}

To Natalina Takahashi de Mello, Medical Mycology Laboratory, and Gil Benard, Laboratory of Medical Investigation Clinics of Infectious and Parasitic Diseases, for carefully reviewing the manuscript.

\section{REFERENCES}

Bennett JE, Kwon-Chung KJ, Theodore TS 1978. Biochemical differences between serotypes of Cryptococcus neoformans. Sabouraudia 16: 167-174.

Borba CM, Rodrigues KF 2000. Viability and sporulating capability of Coelomycetes preserved under a range of different storage regimes. Rev Iber Micol 17: 142-145.

Bosmans J 1974. Ten years lyophilization of pathogenic fungi. Mycopathol Mycol Appl 53: 13-23.

Castellani A 1963. The "water cultivation" of pathogenic fungi. J Trop Med Hyg 66: 283-284.

Castellani A 1967. Maintenance and cultivation of the common pathogenic fungi of man in sterile distilled water. Further researches. Am J Trop Med Hyg 70: 181-184.

Cavalcanti MS, Cavalcanti MAQ 1994. Viabilidad y esporulación en el tiempo de Coelomycetes de la micoteca - URM (Recife-Brasil) conservados bajo aceite mineral. Bol Micol
9: 19-23.

Chen S, Sorrell T, Nimmo G, Speed B, Currie B, Ellis D, Marriott D, Pfeiffer T, Parr D, Byth K 2000. Epidemiology and host variety dependent characteristics of infection due to Cryptococcus neoformans in Australia and New Zealand. Australasian Cryptococcal Study Group. Clin Infect Dis 31: 499-508.

Cherniak R 1988. Soluble polysaccharides of Cryptococcus neoformans. In MR McGinnis, Curr Top Med Mycol, Springer, Verlag, New York, p. 40-54.

Chiapello LS, Aoki MP, Rubinstein HR, Masih DT 2003. Apoptosis induction by glucuronoxylomannan of Cryptococcus neoformans. Med Mycol 41: 347-353.

Diaz MR, Boekhout T, Theelen B, Fell JW 2000. Molecular sequence analyses of the intergenic spacer (IGS) associated with rDNA of the two varieties of the pathogenic yeast, Cryptococcus neoformans. Syst Appl Microbiol 23: 535545.

Dismukes WE 1988. Crypcococcal meningitis in patients with AIDS. $J$ Infect Dis 157: 624-628.

Ellerbroek PM, Walenkamp AM, Hoepelman Al, Coejaet FE 2004. Effects of the capsular polysaccharides of Cryptococcus neoformans on phagocyte migration and inflammatory mediators. Curr Med Chem. 11: 253-266.

Franzot SP, Salkin IF, Casadevall A 1999. Cryptococcus neoformans var. grubii: separate varietal status for Cryptococcus neoformans serotype A isolates. J Clin Microbio. 37: 838-840.

Hoang L, Maguire MJA, Doyle P, Fyfe M, Roscoe DL 2004 Cryptococcus neoformans infections at Vancouver Hospital and Health Sciences Centre (1997-2002): epidemiology, microbiology and histopathology. Med Microbiol 53: 935-940.

Horta JA, Staats CC, Casali AK, Ribeiro AM, Schrank IS, Schrank A, Vainsteins MH 2002. Epidemiological aspects of clinical and environmental Cryptococcus neoformans isolates in the Brazilian state Rio Grande do Sul. Med Mycol 40: 565-571.

Igreja RP, Lazera MS, Wanke B, Galhardo MC, Kidd SE, Meyer W 2004. Molecular epidemiology of Cryptococcus neoformans isolates from AIDS patients of the Brazilian city, Rio de Janeiro. Med Mycol 42: 229-238.

Jain N, Wickes BL, Keller SM, Fu J, Casadevall A, Jain P, Ragan MA, Banerjee U, Fries B 2005. The molecular epidemiology of clinical Cryptococcus neoformans strains from India. J Clin Microbiol 43: 5733-5742.

Kurtzman CP, Fell JW 1998. The Yeasts. A Taxonomic Study, Elsevier's, Amesterdam.

Kwon-Chung KJ 1992. Cryptococcosis. In KJ Kwon-Chung, JE Bennett (eds), Med Mycol, Lea \& Febiger, Philadelphia, p. 397-446.

Kwon-Chung KJ, Polacheck I, Bennett JE 1982. Improved diagnostic medium for separation of Cryptococcus neoformans var. neoformans (Serotype A and D), and Cryptococcus neoformans var. gatti (Serotype B and C). J Clin Microbiol 15: 535-537.

Lacaz CS, Porto E, Martins JEC, Heins-Vaccari EM, Mello NT 2002. Tratado de Micologia Médica, 9 ed., Sarvier, São Paulo, 1104 pp. 
Lacaz CS, Rodrigues MC 1983. Sorotipagem do Cryptococcus neoformans. Rev Bras Med 40: 297-300.

Lima RF, Borba CM 2001. Viability, morphological characteristics and dimorphic ability of fungi preserved by different methods. Rev Iber Micol 18: 191-196.

Litvintseva AP, Thakur R, Reller LB, Mitchell TG 2005. Prevalence of clinical isolates of Cryptococcus gattii serotype $\mathrm{C}$ among patients with AIDS in sub-Saharan. Africa $J$ Infect Dis 192: 888-892.

McGinnis MR 1980. Laboratory Handbook of Medical Mycology, Academic Press, New York, 371 pp.

Mendes da Silva AM, Borba CM, Oliveira PC, 1994. Variability and morphological alterations of Paracoccidioidis brasiliensis strains preserved under mineral oil for long periods of time. Mycoses 37: 165-169.

Nakamura Y 2001. Molecular analyses of the serotype of Cryptococcus neoformans. Nippon Ishinkin Gakkai Zasshi 42: 69-74.

Palella Jr FJ, Delaney KM, Moorman AC, Loveless MO, Fuhrer J, Satten GA, Aschman DJ, Holmberg SD 1998. Declining morbidity and mortality among patients with advanced human immunodeficiency virus infection. HIV Outpatient Study Investigators. $N$ Engl J Med 338: 853-860.

Piot P, Bartos M, Ghys PD, Walker N, Schwartlander B 2001. The global impact of HIV/AIDS. Nature 410: 968-973.

Powderly WG 1993. Cryptococcal meningitis and AIDS. Clin Infect Dis 17: 837-842.

Rodrigues EG, Lírio VS, Lacaz CS 1992. Preservação de fungos e actinomicetos de interesse médico em água destilada. Rev Inst Med Trop São Paulo 34: 159-165.

Saag MS, Powderly WG, Cloud GA, Robinson P, Grieco MH, Sharkey PK, Thompson SE, Sugar AM, Tuazon CU, Fisher JF 1992. Comparison of amphotericin B with fluconazole in the treatment of acute AIDS-associated cryptococcal meningitis. The NIAID mycoses study group and the AIDS clinical trials group. N Engl J Med 326: 83-89.

Sandhu GS, Kline BC, Stockman L, Roberts GD 1995. Molecular probes for diagnosis fungal infections. J Clin Microbiol 33: 2913-2919.

Spencer JFT, Spencer DM 1996. Maintenance and culture of yeasts. Methods Mol Biol 53: 5-15.

Urdaneta SM, Lacaz CS 1965. Preservation of fungi in distilled water preliminary results. Rev Inst Med Trop São Paulo 71:24-26.

van der Horst CM, Saag MS, Cloud GA, Hamill RJ, Graybill JR, Sobel JD, Johnson PC, Tuazon CU, Kerkering T, Moskovitz BL, Powderly WG, Dismukes WE 1997. Treatment of cryptococcal meningitis associated with the acquired immunodeficiency syndrome. National Institute of Allergy and Infectious Diseases Mycoses Study Group and AIDS Clinical Trials Group. N Engl J Med 337: 15-21.

Velegraki A, Kiosses VG, Pitsouni H, Toukas D, Daniilidis VD, Legakis NJ 2001. First report of Cryptococcus neoformans var. gatti serotype B from Greece. Med Mycol 39: 419412.

William JGK, Kubelik AR, Livak KJ, Rafalski, JA, Tingey SV 1990. DNA polymorphisms amplified by arbitrary primers are useful as genetic markers. Nucleic Acids Res 18: 65316535 . 
